\title{
The Editors
}

Christian Kanzian

Department of Philosophy, Theological Faculty, University of Innsbruck, Austria Christian.kanzian@uibk.ac.at

Edmund Runggaldier

Department of Philosophy, Theological Faculty, University of Innsbruck, Austria (2007-09): Humboldt-University, Berlin, Germany

Edmund.runggaldier@uibk.ac.at

\section{List of Authors}

Krzysztof Abriszewski

Department of Philosophy, Nicholas Copernicus University, Toruń, Poland e-mail: krzabr@umk.pl

Ewa Bińczyk

Department of Philosophy, Nicolas Copernicus University, Torun, Poland Ewa.Binczyk@umk.pl

Andreas Blank

The Cohn Institute for the History and Philosophy of Science and Ideas, Tel Aviv, Israel

andreasblank@hotmail.com

Aleksandra Derra

Department of Philosophy, Nicolas Copernicus University, Toruń, Poland

piotr.raku@skynet.be

Christoph Durt

Department of Philosophy, University of Munich, Germany

info@durt.info

Arnold Eckhart

Department of Philosophy, University of Duesseldorf, Germany

eckhart_arnold@hotmail.com

Maurizio Ferraris

Department of Philosophy, Università di Torino, Italy

maurizio.ferraris@labont.it 
Boris Gubman

Department of Philosophy, Tver-University, Russia

gubman@mail.ru

Peter M.S. Hacker

Saint John's College, University of Oxford, UK

hacker@fyfield.sjc.ox.ac.uk

Jennifer Hornsby

Birkbeck College, University of London, UK

j.hornsby@bbk.ac.uk

John Hyman

The Queen's College, University of Oxford, UK

john.hyman@queens.oxford.ac.uk

Michael Kober

Department of Philosophy, University of Freiburg, Germany

michael.kober@philosophie.uni-freiburg.de

Hans-Herbert Kögler

Department of Philosophy, University of North Florida, USA

hkoegler@unf.edu

Matthias Kroß

Einstein-Forum, Potsdam, Germany

matthias.kross@einsteinforum.de

Marion Ledwig

Department of Philosophy, University of Nevada, USA

marion.ledwig@unlv.edu

Elisabeth Meilhammer

Friedrich Schiller University Jena, Germany

eem@uni-jena.de

Ulrich Metschl

University of Munich / Department of Philosophy, University of Innsbruck, Germany/Austria

ulrich.metschl@1rz.uni-muenchen.de,ulrich.metschl@uibk.ac.at

Alice Pechriggl

Department of Philosophy, University of Klagenfurt, Austria

Alice.Pechriggl@univie.ac.at 
Bernhard Pörksen

Department of Philosophy, University of Hamburg, Germany

bernhard.poerksen@uni-hamburg.de

Patrick Riordan

Heathrop College, London, UK

p.riordan@heythrop.ac.uk

Richard Rorty

Department of Philosophy, University of Stanford, USA

rrorty@stanford.edu

Hans Rott

Department of Philosophy, University of Regensburg, Germany

hans.rott@psk.uni-regensburg.de

Gerhard Schurz

Department of Philosophy, University of Duesseldorf, Germany

gerhard.schurz@phil-fak.uni-duesseldorf.de

Barry Smith

University at Buffalo / Institute for Formal Ontology and Medical Information

Science, Saarland University, USA / Germany

phismith@buffalo.edu

Pirmin Stekeler-Weithofer

Department of Philosophy, University of Leipzig, Germany

stekeler@rz.uni-leipzig.de

Christian Helmut Wenzel

Chi Nan University, Taiwan

wenzelc@ncnu.edu.tw

Franz Martin Wimmer

Department of Philosophy, University of Vienna, Austria

Franz.Martin.Wimmer@univie.ac.at

Kwasi Wiredi

Department of Philosophy, Tampa-University, USA

kwiredu@cas.usf.edu

Leo Zaibert

Department of Philosophy, University of Wisconsin-Parkside, USA

zaibert@uwp.edu 